1 Kahn HA, Milton RC. Alternative definitions of open angle glaucoma. Effect on prevalence and associations in the Framingham eye study. Arch Ophthalmol 1980; 98: 2172-7.

2 Sponsel WE. Tonometry in question: can visual screening tests play a more decisive role in glaucoma diagnosis and management? Surv Ophthalmol 1988; 33 (suppl): 291-300.

3 Rosetti L, Marchetti I, Orzales N, Scorpiglione N, Torri V, Liberati A. Randomized clinical trials of medical treatment of glaucoma, are they appropriate to guide clinical practice? Arch Ophthalmol 1993; 111: 96-103.

4 Jay JL. Medical versus surgical treatment of primary open angle glaucoma. In: Davidson SI, Jay B, eds. Recent advances in ophthalmology. Edinburgh: In: Davidson SI, Jay B, eds. Recent advanc

5 Wilensky JT, Gieser DK. Low tension glaucoma. In: Weinstein GW, ed. Open angle glaucoma. Edinburgh: Churchill Livingstone, 1986: 49-65.

6 Geijssen $\mathrm{CH}$. Studies on normal pressure glaucoma. Amsterdam: Kugler, 1991: 202-9.
7 Smith RJH. The enigma of primary open angle glaucoma. Trans Ophthalmol Soc UK 1986; 105: 618-33.

8 Jay JL, Murdoch JR. The rate of visual field loss in untreated primary open angle glaucoma. Br f Ophthalmol 1993; 77: 176-8.

9 Drance SM. Glaucoma. Changing concepts. Eye 1992; 6: 337-45.

10 Jay JL. The vascular factor in low tension glaucoma: alchemists' gold? Br f Ophthalmol 1992; 72: 1 .

11 King D, Drance SM, Douglas G, Schulzer M, Wijsman K. Comparison of visual field defects in normal tension and high tension glaucoma. of visual field defects in normal tens

12 Glicklich RE, Steinmann WC, Spaeth GL. Visual field change in low tension glaucoma over a five year follow up. Ophthalmology 1989; 96: 316-20.

13 Chauhan BC, Drance SM, Douglas GR, Johnson CA. Visual field damage in normal tension and high tension glaucoma. Am $f$ Ophthalmol 1989; 108: $636-42$.

14 Bloomfield S. The results of surgery in low tension glaucoma. $A m f$ Ophthalmol 1953; 36: 1067-70.

15 de Jong, Greve EL, Hoyng PEG, Geijssen HC. Results of filtering procedure in low tension glaucoma. Int Ophthalmol 1989; 13: 131-8.

\title{
The SLO, yet again
}

In recent years there have been a number of papers demonstrating the versatility of the scanning laser ophthalmoscope (SLO), including its use for fluorescein angiography, ${ }^{12}$ quantification of retinal blood flow, ${ }^{3}$ static fundus controlled perimetry, ${ }^{4}$ and the measurement of optic disc variables. ${ }^{5} 6$ To add to this list we now have the imaging of fundus autofluorescence, described in this issue in the paper by von Rückmann and colleagues ( $p$ 407). They take advantage of two of the major features of the confocal SLO, the ability to image using monochromatic light and the production of an image of a relatively thin slice of tissue. Clearly, the SLO is an extremely versatile instrument; to what extent does it offer the 'ultimate' imaging experience for ophthalmologists?

The concept of using lasers to image the retina was first proposed by Webb and colleagues in $1980^{7}$; the instrument was known initially as the flying spot TV ophthalmoscope, the term 'scanning laser ophthalmoscope' being introduced the following year. The conventional fundus camera illuminates a majority of the fundus simultaneously and so requires a large entrance aperture which, in turn, limits the size of the exit aperture through which the reflected beam can pass. The result is that the illuminating beam needs to be of high intensity. In contrast the SLO uses serial imaging; a narrow beam of laser light is scanned in a raster fashion across the fundus with an image of only one small point on the fundus being made at any one time. This means that a very small input beam of laser light can be used, freeing the rest of the pupil area for the reflected light to exit through. The immediate advantage of the system is that it allows imaging to be carried out at low light levels, some 200 times lower than with the fundus camera. ${ }^{8}$

The image is intrinsically a digitised one, although commercial instruments usually record it as a video signal. The main disadvantage of the instrument is its limited spatial resolution; the optics of the eye restricting the size of the laser spot on the retina to some $15 \mu \mathrm{m}$ in diameter. Thus the SLO will lose some of the fine low contrast detail of the fundus camera. It should be noted, however, that providing the feature to be detected has sufficient contrast then it will be visible, albeit blurred, even though its actual size is much smaller than the spot size.

Apart from the convenience of being able to use low intensity light, the SLO offers a number of interesting features, several of whose potential has not yet been explored fully. The contrast of retinal features can be varied by changing the thickness of section over which reflected light is received, the amount of scattered light detected, and the wavelength of the illuminating beam. The development of the confocal version of the SLO by Webb in $1987^{\circ}$ has led to tomographic imaging and a reduction in the amount of scattered light in the image. Unfortunately, imaging at depth will always depend upon the amount of light penetrating through the overlying layers of tissue and so it is inevitable that the quality of images of the deeper fundal layers will be limited. Also the thinner the section is, the lower will be the amount of light available and, hence, the poorer the quality of the image. There are two ways of addressing this problem; to increase either the strength of the illuminating beam or the exposure time. While the difference between the exposure from the SLO and fundus camera might suggest that the power of the irradiating laser, some $50 \mu \mathrm{W}$, may be safely increased there is, in fact, little information on the effect on retinal tissue of exposure to monochromatic laser light at this level. This is an area in which more work on safe working exposure levels is required.

The solution proposed in von Rückmann et al's paper was to increase the effective exposure time, by summing multiple images. However, this introduces the problem of correcting for eye movement. Unfortunately, the registration of images requires not simply corrections for shift but also image warping, and manual alignment of the images is often not sufficient for this. Much effort has been expended upon algorithms for movement correction of retinal images, ${ }^{10}$ these are sophisticated but, as a result, often very time consuming even on modern workstations. This may prove to be the factor that limits the value of this technique.

A further problem is that there is little information as to the size of tomographic sections produced by the SLO. Although some workers have produced results measuring slice thickness, ${ }^{11-13}$ the manufacturers of commercial instruments often only identify the confocal aperture by a number and do not provide information about slice thickness. In practice, the slice thickness needed to produce an image of reasonable quality appears to be about $2500 \mu \mathrm{m},{ }^{13}$ thinner slices being too noisy. This must surely raise questions as to the value of the instrument for measuring retinal topography. While there have been published results showing the technique to be reproducible, ${ }^{14}$ measurements made on humans have had certain inconsistencies in the values produced ${ }^{6}$ which have not been convincingly explained.

Perhaps the most interesting feature of the instrument is 
the ability to image at different wavelengths. At present the most convenient source of laser light is the diode laser, which is compact, simple to operate, and cheap to purchase. Unfortunately, the range of wavelengths available is limited and for wavelengths shorter than $660 \mathrm{~nm}$ it is necessary to use a gas or dye laser. Given a range of wavelengths, it may be possible to study variables such as tissue blood flow, volume, and oxygenation; work that has already been successfully carried out in a non-imaging mode on cerebral tissue. ${ }^{15} 16$

In their paper, von Rückmann and colleagues capture the SLO images on a video recorder and then digitise the video image, which will inevitably lead to a loss of image quality. The SLO is ideal for direct digital imaging as the serial nature of the image process effectively produces a digital image. The addition of a relatively cheap PC with an image grabber card permits rapid acquisition of sequential SLO images, such as would be required in fluorescein angiography. The value of making quantitative measurements of pathology from digitised fundus camera images has been demonstrated ${ }^{17-19}$ as such measurements can provide new information about the clinical status of the fundus. But digital imaging may be a mixed blessing. For example, while it avoids the need to develop film an angiographic sequence may require substantial storage requirements that challenges even that available from optical disks. In addition, the provision of an adequate numbers of suitable image viewing terminals needs to be taken into account. It may be that at the present time the adoption of digital imaging technology for other than very specialised tasks should be made only after very careful evaluation.

Whatever the problems, the confocal SLO undoubtedly offers a very versatile instrument for retinal imaging. However, much work is still required to realise its full potential. The study of autofluorescence is yet another exciting application, and an assessment of its clinical value is eagerly awaited.

Department of Biomedical Physics and Bioengineering,

P F SHARP

University of Aberdeen, Foresterhill,

Aberdeen AB9 2ZD
1 Scheider A, Schrodel C. High resolution indocyanine green angiography with a scanning laser ophthalmoscope. Am f Ophthalmol 1989; 108: 458-9.

2 Nasemann JE, Muller M. Scanning laser angiography. In: Nasemann JE, Burk ROW, eds. Scanning laser ophthalmoscopy and tomography. Munich: Qunitessenz Verlags, 1990: 63-80.

3 Wolf S, Koyama T, Meyer-Ebrecht D, Reim M. Scanning laser ophthalmoscopy for the quantification of retinal blood flow parameters: a new imaging technique. In: Nasemann JE, Burk ROW, eds. Scanning laser ophthalmoscopy and tomography. Munich: Qunitessenz Verlags, 1990: 91-6.

4 Sturmer J, Schrodel C, Rappl W. Scanning laser ophthalmoscope for static fundus-controlled perimetry. In: Nasemann JE, Burk ROW, eds. Scanning laser ophthalmoscopy and tomography. Munich: Qunitessenz Verlags, 1990: 133-46.

5 Burk ROW, Rohrschneider K, Volcker HE, Zinser G. Analysis of threedimensional optic disk topography by laser scanning tomography. In: Nasemann JE, Burk ROW, eds. Scanning laser ophthalmoscopy and tomography. Munich: Qunitessenz Verlags, 1990: 161-76.

6 Janknecht P, Funk J. Optic nerve head analyser and Heidelberg retina tomograph: accuracy and reproducibility of topographic measurements in a model eye and in volunteers. Br $\mathcal{F}$ Ophthalmol 1994; 78: 760-8.

7 Webb RH, Hughes GW, Pomerantzeff O. Flying spot TV ophthalmoscope. Applied Opt 1980; 19: 2991-7.

8 Manivannan A, Sharp PF, Phillips RP, Forrester JV. Digital fundus imaging using a scanning laser ophthalmoscope. Physiol Meast 1993; 14: 43-56.

9 Webb RH, Hughes GW, Delori FC. Confocal scanning laser ophthalmoscope. Applied Opt 1987; 26: 1492-9.

10 Jagoe R, Blauth CI, Smith PL, Arnold JV, Taylor K, Wootton R. Automatic geometric registration of fluorescein retinal angiograms. Comp Biomed Res 1990; 23: 403-9.

11 Plesch A, Klingbeil U. Optical characteristics of a scanning laser ophthalmoscope. SPIE 1989; 1161: 390-8.

12 Woon WH, Fitzke FW, Bird AC, Marshall J. Confocal imaging of the fundus using a scanning laser ophthalmoscope. Br f Ophthalmol 1992; 76: $470-4$.

13 Manivannan A, Sharp PF, Forrester JV. Performance measurements of an infrared digital scanning laser ophthalmoscope. Physiol Meast 1994; 15: 317-24.

14 Cioffi GA, Robin AL, Eastman RD, Perell HF, Sarfarazi FA, Kelman SE. Confocal laser scanning ophthalmoscope. Reproducibility of optic nerve head topographic measurements with the confocal laser scanning ophthalmoscope. Ophthalmology 1993; 100: 57-62.

15 Cope M, Delpy DT. A system for long term measurement of cerebral blood and tissue oxygenation in newborn infants by near-infrared transillumination. Med Biol Eng Comput 1988; 26: 289-94.

16 Wyatt JS, Cope M, Delpy DT, Richardson CE, Edwards AD, Wray S, Richards EOR. Quantitation of cerebral blood volume in human infants by near-infrared spectroscopy. $\mathcal{F}$ Appl Physiol 1990; 68: 1086-91.

17 Phillips RP, Ross PGB, Sharp PF, Forrester JV. Use of temporal information to quantify vascular leakage in fluorescein angiography of the retina. Physiol Meast 1990; 11 (Suppl A): 81-5.

18 Phillips RP, Spencer T, Ross PGB, Sharp PF, Forrester JV. Quantification of diabetic maculopathy by digital imaging of the fundus. Eye 1991; 5: $130-7$.

19 Phillips R, Forrester JV, Sharp P. Automated detection and quantification of retinal exudates. Graefes Arch Clin Exp Ophthalmol 1993; 231: $90-4$. 